\title{
REVISITANDO O CONCEITO DE AUTONOMIA NO ENSINO-APRENDIZAGEM DE LÍNGUAS COMO SISTEMA ADAPTATIVO COMPLEXO'
}

RESUMO: O presente trabalho tem por objetivo revisitar o conceito de autonomia no contexto de ensino-aprendizagem de línguas e discutir, à luz da teoria da complexidade, a noção de autonomia como sistema adaptativo complexo. Para contextualizar as discussões aqui propostas, este artigo inicia-se com uma descrição do cenário brasileiro em pesquisas sobre autonomia no ensino-aprendizagem de línguas e, depois, discute a noção de autonomia subjacente a quatro importantes teorias de aquisição de segunda língua. Em seguida, apresenta as diferentes definições existentes na literatura para o termo autonomia e, com base nos pressupostos teóricos da teoria da complexidade, focaliza a visão de autonomia como sistema adaptativo complexo. Por fim, desenvolve algumas considerações importantes para se repensar a questão da autonomia no ensino-aprendizagem de línguas.

Palavras-chave: Autonomia; Ensino-Aprendizagem de Línguas; Complexidade.

\section{REVISITING THE CONCEPT OF AUTONOMY IN LANGUAGE TEACHING AND LEARNING AS A COMPLEX ADAPTIVE SYSTEM}

Abstract: This paper aims at revisiting the concept of autonomy in the context of language teaching and learning, and discussing, in the light of complexity theory, the notion of autonomy as a complex adaptive system. To contextualize the proposed discussions, this article begins with an overall description of the scenario of research on autonomy in the language teaching and learning in Brazil, and thus discusses the notion of autonomy underlying four major theories of second language acquisition. Then, different definitions for the term autonomy are presented and, based on the theoretical framework for complexity theory, the focus is shifted to the concept of autonomy as a complex adaptive system. Finally, some important considerations are raised to rethink the issue of autonomy in the scope of language teaching and learning. Keywords: Autonomy; Language Teaching and Learning; Complexity.

\footnotetext{
* Doutor em Linguística Aplicada pela Universidade Federal de Minas Gerais (UFMG); Professor da Faculdade de Letras da Universidade Federal do Rio de Janeiro (UFRJ). E-mail: cpaivafranco@yahoo.com.br
} 


\section{Introdução}

No atual panorama brasileiro sobre estudos em autonomia, mais especificamente, no contexto de ensino-aprendizagem de línguas, alguns pesquisadores (MAGNO; SILVA, 2008; NICOLAIDES, 2003, 2005, 2010; NICOLAIDES; FERNANDES, 2008; PAIVA, 2005a, 2005b, 2006, 2011; PAIVA; BRAGA, 2008; SPRENGER, 2004; SPRENGER; WADT, 2008) têm investigado a questão da autonomia sob diferentes olhares e em diferentes contextos. O periódico Documentação de Estudos em Linguística Teórica e Aplicada (Delta) publicou um número especial sobre autonomia, em 2008, reunindo artigos dos referidos pesquisadores brasileiros. A seguir, serão apresentados, de forma breve, quatro desses trabalhos que se tornaram referência na literatura.

Fundamentadas na literatura sobre autonomia do professor e do aluno, na Pedagogia Crítica e em estudos sobre narrativas do professor e do aluno, Sprenger e Wadt (2008) descrevem o processo de reformulação de um plano de curso que objetiva o desenvolvimento da autonomia de professores de línguas para planejamento de curso e preparação de materiais didáticos. As autoras concluem com alguns questionamentos sobre as decisões teóricas e práticas tomadas na segunda versão do curso e sobre suas implicações.

A pesquisadora Magno e Silva (2008) apresenta um modelo para o fomento da autonomia dos aprendizes, mostra alguns resultados alcançados na aplicação desse modelo, durante três anos, com alunos do curso de Letras, e discute desafios ainda a serem enfrentados. O modelo comporta a investigação de áreas problemáticas do processo individual de aprendizagem de cada sujeito, a identificação de seus estilos preferenciais de aprender, o uso de ferramentas tecnológicas para melhorar a autonomia na aprendizagem, o desenvolvimento de um leque maior de estratégias de aprendizagem de línguas e a implementação de rotinas de automonitoramento e autoavaliação. Os dados revelam, principalmente, que o modelo provou sua eficácia em prover um andaime para a aprendizagem autônoma de línguas dos alunos.

À luz da Pedagogia Crítica de Freire, Nicolaides e Fernandes (2008) enfatizam o fato de que a autonomia do aprendiz é também uma questão de envolver-se com o ambiente social no qual está inserido. $\mathrm{O}$ 
estudo de caso oferece tipos de transformações que podem acontecer, influenciadas pelo meio e pelas oportunidades nele geradas.

As pesquisadoras Paiva e Braga (2008) revisitam alguns conceitos de autonomia na aprendizagem de línguas e utilizam, à luz da teoria do caos/complexidade, evidências empíricas para defender a perspectiva de autonomia como fenômeno complexo. Em estudo realizado com 16 narrativas de aprendizagem de língua inglesa, coletadas no Brasil e parte integrante do corpus de narrativas do Projeto AMFALE (Aprendendo com Memórias de Falantes e Aprendizes de Língua Estrangeira), ${ }^{2}$ as autoras concluem que, apesar dos obstáculos encontrados pelos aprendizes, a autonomia os leva a procurar experiências mais significativas de aprendizagem. Anterior ao trabalho de Paiva e Braga (2008), o estudo de Paiva (2006) é o primeiro no Brasil a adotar a perspectiva da complexidade para entender a autonomia de aprendizes de línguas. Seu principal objetivo é oferecer evidências empíricas para que a autonomia seja vista como um fenômeno complexo e, para isso, utiliza narrativas de um perfil de aprendizes bastante heterogêneo.

Além dos artigos publicados pelo periódico Delta, em 2008, no número especial sobre autonomia, quatro teses merecem destaque e são apresentadas a seguir.

Nicolaides (2003), em sua tese $A$ busca da aprendizagem autônoma de lingua estrangeira no contexto acadêmico, analisa o processo de autonomia de nove alunos do curso de Letras (Português-Inglês). Com base no entendimento de indivíduo autônomo como aquele que é responsável pela própria aprendizagem, os resultados da referida pesquisa etnográfica mostram que a verificação da autonomia de um aprendiz depende de uma série de fatores. Nicolaides conclui que é preciso que se repensem os papéis de diversos integrantes do cenário educacional e se descubra como o aprendiz pode-se tornar mais responsável pela busca de seu conhecimento.

Em Conscientização e autonomia em formação on-line de professores, Sprenger (2004) explora a autonomia na formação de professores em contextos de ensino on-line. A partir do entendimento de autonomia como um caminho a ser percorrido, a pesquisa buscou analisar, à luz da teoria da atividade, o processo de desenvolvimento da autonomia de quatro professoras-alunas em um curso on-line de formação continuada de professores. Além disso, Sprenger investigou de que forma o diá- 
logo crítico e reflexivo, essencial no desenvolvimento da autonomia, foi viabilizado no ambiente digital.

$\mathrm{Na}$ pesquisa de Fernandes (2005), As crenças e a práxis de professores de lingua inglesa em formação e o aprendizado autônomo, relata-se como alunos-estagiários do curso Licenciatura em Inglês percebem o papel do aluno e o do professor em sala de aula, como avaliam seu desempenho como alunos, durante seu curso de graduação, e o sistema instrucional. Os resultados revelam que os participantes consideram, teoricamente, a autonomia como um aspecto importante na formação do indivíduo e na aprendizagem de uma língua estrangeira, percebendo, de forma clara, as diferentes nuances entre os papéis do aluno e do professor. Fernandes também observou que apenas duas participantes alteraram suas atitudes e/ou crenças.

Moura Filho (2005), no estudo de caso Pelo inglês afora: carreira profissional e autonomia na aprendizagem de inglês como língua estrangeira, pretende analisar os intervenientes na aprendizagem autônoma de inglês e destacar as possibilidades de conciliação entre essa alternativa pedagógica e a carreira profissional dos aprendizes. Os resultados das análises realizadas indicam que os processos de autonomia na aprendizagem de inglês são vivenciados de forma intuitiva e não como decorrência de planejamento dele e/ou de algum de seus professores.

Como se pode observar, alguns pesquisadores brasileiros vêmse dedicando ao estudo da autonomia em contextos de ensino-aprendizagem de línguas, mas ainda são poucos os que propõem investigar essa questão sob as lentes da teoria do caos/complexidade. Antes de se abordar essa visão em particular, a próxima seção deste artigo atém-se às concepções de autonomia subjacentes a quatro importantes teorias de aquisição de segunda língua (ASL).

\section{Autonomia no ensino de línguas}

Ao longo da história do ensino de línguas, pode-se observar que as diferentes teorias de ASL adotavam uma visão de linguagem específica e, consequentemente, tratavam da autonomia sob uma perspectiva diferente. Consequentemente, algumas abordagens eram mais centradas no professor e outras no aluno. Para que se entenda a visão de 
autonomia predominante em cada momento no ensino de línguas, a presente seção é organizada com base em quatro importantes teorias de ASL: behaviorismo, gramática universal, aculturação e socioculturalismo.

\section{Behaviorismo}

$\mathrm{Na}$ concepção behaviorista, a aprendizagem de línguas é vista como qualquer outro tipo de aprendizagem: formação de hábitos. Segundo Mitchell e Myles (2004, p.30), a aprendizagem de qualquer tipo de comportamento estava baseada nas noções de estímulo e resposta. Por meio da repetição, um determinado estímulo vai exigir a mesma resposta diversas vezes até que se constitua em um hábito. Assim, duas implicações pedagógicas no behaviorismo eram: (i) como a prática leva à perfeição, a aprendizagem ocorreria ao imitar e repetir a mesma estrutura várias vezes; (ii) o foco deveria ser no ensino de estruturas complexas, ou seja, aquelas que são diferentes entre duas línguas.

Um método de ensino norteado pelos princípios da psicologia comportamental foi o audiolingual. A concepção predominante de linguagem estava pautada no estruturalismo, ou seja, a ênfase, nessa concepção de linguagem, era o produto linguístico e não o processo cognitivo ou social. A aprendizagem de língua materna (L1) era vista como um processo relativamente simples, em que o falante aprendia um conjunto de hábitos novos em resposta ao estímulo do ambiente. Ao aprender uma L2, por já se ter um conjunto de hábitos definidos na L1, o processo de aprendizagem implica a substituição de hábitos antigos por novos. Segundo Dulay et al. (1982, p.99), a interferência dos hábitos já adquiridos poderia facilitar (se as estruturas gramaticais da L1 são parecidas com as da L2) ou dificultar (se as estruturas da L1 são diferentes das da L2) o processo de aprendizagem de L2.

Nas abordagens metodológicas que seguem o behaviorismo, o ensino de línguas está centrado unicamente na figura do professor. Como não há oportunidades para o aluno criar situações de aprendizagem, o enfoque está nas condições de aprendizagem oferecidas pelas situações físicas como a sala de aula, o ambiente domiciliar, o centro de autoacesso. Trata-se da perspectiva técnica da autonomia, em que ela é vista como sinônimo para aprendizagem independente, ou melhor, 
autoinstrução, já que "a pessoa aprende sozinha sem o apoio do professor, orientador ou da instituição"3 (OXFORD, 2003, p.82). Nas palavras de Dickinson (1987, p.11), a noção de autonomia, nessa perspectiva, refere-se à "situação na qual o aprendiz é totalmente responsável pelas decisões sobre a sua aprendizagem e a implementação dessas decisões."

Pouco antes da década de 1960, a linguística passou por uma grande mudança: da linguística estrutural, que se baseava na descrição das estruturas da língua, para a gerativa, que enfatizava a natureza criativa da linguagem humana. No campo da psicologia, o papel do ambiente perdia espaço para visões mais direcionadas para o desenvolvimento da aprendizagem, por exemplo, a teoria de desenvolvimento cognitivo de Piaget, influenciando a concepção de autonomia no ensino de línguas, como se pode verificar no próximo item.

\section{Gramática universal}

Com o início do gerativismo, Chomsky (1959) argumentou que a competência linguística de um falante não pode ser reduzida a um modelo baseado em imitação e formação de hábitos e, para isso, baseouse em questões como a criatividade inerente à língua. Para ele, crianças não aprendem e reproduzem uma vasta gama de frases, mas criam, constantemente, novas frases que nunca aprenderam antes. Chomsky afirmou que as crianças têm uma faculdade inata, uma gramática universal, que as guia na aprendizagem de línguas. Essas afirmações de Chomsky se baseavam no fato de que as crianças seguem algum tipo de rota interna pré-programada, ao adquirir uma língua.

Segundo Kern e Warschauer (2000), a teoria chomskiana contribuiu para uma mudança gradual de objetivos no ensino de línguas: de incutir hábitos linguísticos precisos para promover a construção mental de um sistema de segunda língua. Com isso, a aprendizagem de línguas passou a ser entendida não como uma resposta condicionada, mas como um processo ativo de gerar e transformar conhecimento.

Nesse período do ensino de línguas, a autonomia do aprendiz é vista sob uma perspectiva psicológica, isto é, o enfoque está nas "características mentais e emocionais dos aprendizes, que são vistos como indivíduos (psicologia individual)" (OXFORD, 2003, p.83). O 
agenciamento, portanto, é visto como uma característica psicológica do indivíduo.

No ensino de línguas, o Método Silencioso (The Silent Way), em que o ato de ensinar deveria estar subordinado ao de aprender - representado pelo silêncio do professor - é orientado pelos princípios da teoria chomskiana. Ainda sobre o Método Silencioso, Larsen-Freeman (2000, p.65) afirma que os aprendizes "ganham autonomia na língua ao explorá-la e ao fazer escolhas". ${ }^{6}$ Isso acontece, por exemplo, quando o professor pede para que os alunos descrevam suas reações em relação à aula ou quando eles expõem o que aprenderam. Dessa forma, nas palavras da autora, os alunos "assumem responsabilidade pela sua própria aprendizagem” (LARSEN-FREEMAN, 2000, p.65).?

\section{Aculturação}

Schumann (1978) propõe que a investigação de fatores que interferem no processo de ASL aconteça no contexto natural, isto é, no ambiente em que a língua é falada. Para ele, uma língua, diferentemente de disciplinas como História ou Matemática, pode ser aprendida sem instrução formal. O modelo da aculturação é aplicado à ASL principalmente em casos de imigração.

Dos fatores que influenciam a ASL, Schumann destaca dois: o social e o afetivo. $O$ autor agrupa essas duas variáveis em uma única categoria, que ele chama de aculturação, ou seja, a integração social e psicológica do aprendiz com o grupo da língua alvo. Ele acredita que o aprendiz só vai adquirir a L2 se ele sofrer aculturação. Existem dois tipos de aculturação. No primeiro tipo, o aprendiz está socialmente integrado com o grupo da língua alvo, estando aberto psicologicamente a esse grupo e, assim, absorve o insumo. No segundo tipo de aculturação, além de reunir todas as características do primeiro, o aprendiz deseja pertencer à comunidade de falantes da língua alvo, adotando seus estilos de vida e valores. Os dois tipos são suficientes para a ASL, em que os contatos social e psicológico são elementos fundamentais para a aculturação. Vale destacar que não importa qual método de ensino seja adotado; em algum momento do processo de aprendizagem, os resultados não serão satisfatórios 
porque a aprendizagem de línguas não é uma questão de método, mas de aculturação.

Pode-se dizer que, na aculturação, a autonomia do aprendiz, assim como no gerativismo, é vista sob uma perspectiva psicológica, mas o enfoque, dessa vez, está no aprendiz como membro "de um grupo social ou cultural bastante generalizado (psicologia social)"8 (OXFORD, 2003, p.83).

Ao comparar os contextos de aprendizagem de alunos de L2 e língua estrangeira (LE), Green e Oxford (1995) concluem que os contextos de aprendizagem de alunos de L2 - em que há grande fluxo de comunicação diária entre as pessoas - são mais ricos em propiciamentos para usar o idioma. De forma simples, esses contextos oferecem um maior número de oportunidades para os aprendizes praticarem o idioma. O mesmo não pode ser dito sobre os contextos de aprendizagem daqueles que estudam o idioma como LE, isto é, em contextos comunicativos que não representam o maior veículo de comunicação entre falantes nativos da língua.

\section{Socioculturalismo}

A teoria sociocultural tem sua origem nos trabalhos do psicólogo Lev Vygotsky (1978). Essa corrente teórica advoga que o funcionamento mental humano é um processo fundamentalmente mediado, que é organizado por artefatos, atividades e conceitos culturais. Processos de desenvolvimento ocorrem por meio da participação em contextos culturais, linguísticos e históricos como vida familiar, interação em grupo com colegas e em contextos institucionais como na escola, em atividades desportivas organizadas e no ambiente de trabalho. As formas mais importantes de atividade cognitiva se desenvolvem através da interação nesses contextos sociais e materiais. Além disso, a linguagem é o artefato cultural mais difundido e poderoso que o homem tem para mediar sua conexão com o mundo, o outro e si mesmo.

Um dos conceitos mais importantes no socioculturalismo é o de zona de desenvolvimento proximal (ZDP), que representa "a distância entre o real nível de desenvolvimento determinado pela resolução independente de problemas e o nível do desenvolvimento potencial 
determinado pela resolução de problema por meio da orientação de um adulto ou em colaboração com parceiros mais capazes" (VYGOTSKY, 1978, p.86).

Segundo estudos de Vygotsky, a aprendizagem colaborativa, particularmente em contextos instrucionais, precede e modela o desenvolvimento. Ambientes de aprendizagem que foram intencionalmente organizados podem estimular mudanças qualitativas de desenvolvimento. Sobretudo, o desenvolvimento surge da interação dialógica que transpira entre indivíduos. Devido ao fato de essa perspectiva conceber a linguagem como uma ferramenta cultural usada para conduzir atividades guiadas por um objetivo, tarefas como testes tradicionais de língua, elaboradas para verificar o conhecimento linguístico do aprendiz, apresentam evidências insuficientes de desenvolvimento. As tarefas devem ser, portanto, elaboradas com base em situações reais ou em programas instrucionais no contexto de sala de aula como em aprendizagem baseada em projetos. No ensino de línguas, conforme Kern e Warschauer (2000) explicam, os aprendizes devem-se engajar em situações e comunidades discursivas autênticas, encontradas fora da sala de aula. Apareceram, então, os modelos de aprendizagem baseados em tarefas ("task-based learning") e por conteúdo ("content-based learning").

Essa ênfase no aprendiz por meio da aprendizagem socialmente mediada está diretamente adjunta à perspectiva sociocultural de autonomia. Segundo Oxford (2003), pode-se dividir a perspectiva sociocultural (também conhecida como sociointeracionista) em I e II. Na sociocultural I, a autonomia é autorregulada, resultado da interação social com um mediador mais competente, podendo a mediação ocorrer por parte de um outro aprendiz, professor, livros, ou até mesmo a tecnologia. O agenciamento é entendido como o poder de controlar a própria aprendizagem por meio da autorregulação. Na sociocultural II, "o aprendiz não é tão importante quanto a participação na comunidade; e essa perspectiva enfatiza o contexto da autonomia em detrimento de o indivíduo exercê-la" (OXFORD, 2003, p.87). ${ }^{9}$ O agenciamento envolve a participação ativa em uma atividade de cognição com a ajuda de um parceiro mais experiente.

Como se pode notar, a promoção da autonomia no ensino de línguas é algo claramente desejável. Segundo Benson (2001), os professores devem apoiar os seus alunos a utilizar métodos diferentes, já que 
a autonomia assume várias formas e não existe um único método para fomentá-la no aprendiz. Para compreender melhor o conceito de autonomia, são apresentadas, na próxima seção, algumas definições consagradas na literatura para o referido termo.

\section{Autonomia: algumas definições}

O termo "autonomia", geralmente associado à expressão "autonomia do aprendiz" (learner autonomy), estabelecida por Carl Rogers (1969), refere-se à habilidade que todos os aprendizes possuem, em diferentes níveis, de desenvolver um planejamento de estudo pessoal, de encontrar materiais para pesquisar e de avaliar, por si mesmos, o progresso (ou não) de sua aprendizagem. Rogers afirma que um dos princípios para a aprendizagem - fundamental para o conceito de autonomia - é a liberdade de escolha. Pode-se entender, portanto, que aprendizes autônomos são aqueles indivíduos livres para decidir a maneira mais adequada de atingir seus objetivos de aprendizagem.

Emprega-se o termo autonomia, geralmente, relacionado às ideias de independência, liberdade, controle, monitoramento, gerenciamento, responsabilidade, entre outras. Para Benson e Voller (1997), o termo "autonomia" pode ser empregado para designar: (i) situações em que os aprendizes estudam inteiramente por conta própria; (ii) um conjunto de habilidades que podem ser aprendidas e aplicadas para a autoaprendizagem; (iii) uma capacidade inata que é suprimida pela educação institucional; (iv) o exercício da responsabilidade dos alunos pela sua própria aprendizagem; (v) o direito dos alunos para determinar a direção de sua própria aprendizagem.

Holec (1981) é o primeiro teórico a apresentar uma definição seminal para autonomia no contexto de ensino de línguas - "a habilidade de cuidar de sua própria aprendizagem” (HOLEC, 1981, p.3). Essa definição de Holec para autonomia é consagrada na literatura e influenciou o trabalho de outros teóricos (LITTLE, 1991; DICKINSON, 1995; COTTERALL, 1995). Para eles, a autonomia está relacionada, fundamentalmente, à responsabilidade que o aprendiz possui sobre a sua própria aprendizagem. Dessa forma, a partir do momento em que o indivíduo passa a ter controle da própria aprendizagem, buscando 
fontes que o ajudem a desenvolver seu potencial, ele adquire graus de autonomia. Em termos práticos, isso significa dizer que o aluno desenvolve uma postura cada vez mais autônoma ao assumir maior responsabilidade por componentes essenciais na aprendizagem, desde especificar os objetivos e conteúdos de estudo, através da seleção de métodos e técnicas, até monitorar e avaliar o próprio processo de aprendizagem.

Little (1991) se propõe a apresentar uma visão mais detalhada sobre autonomia na aprendizagem de línguas e, para isso, lista uma série de itens que se referem ao que autonomia não é: (i) autonomia não é sinônimo para autoinstrução; (ii) autonomia não implica a abdicação de responsabilidades por parte do professor; (iii) autonomia não é um método de ensino; (iv) autonomia não é um comportamento único, facilmente descrito; (v) autonomia não é um estado de equilíbrio alcançado pelos aprendizes.

Em relação ao item (i), Paiva (2006) argumenta que estudar sozinho (autoinstrução) não representa necessariamente ter uma atitude autônoma, pois as decisões e o percurso sobre o que estudar são, na maioria das vezes, oferecidos pelo material didático. Entende-se, dessa maneira, que a autonomia está relacionada, de uma forma mais geral, à tomada de decisões em relação à aprendizagem como as escolhas sobre o que, como e quando estudar. Essas escolhas são individuais e podem ocorrer quando o aprendiz interage com o material didático, o professor, um colega mais ou menos experiente ou em uma sala de aula.

Dickinson (1995) esclarece que a "capacidade" de ser responsável pela própria aprendizagem deve implicar a capacidade de os aprendizes internalizarem um sistema que pode acompanhá-los não só na sala de aula, mas também em contextos fora da sala de aula, tais como em centros de autoacesso. Outro exemplo de manifestação da autonomia em contextos informais de aprendizagem é o uso de novas tecnologias, mais especificamente a internet, como será discutido detalhadamente, mais adiante.

Para outros autores (PENNYCOOK, 1997; BENSON; 1997; FREIRE, 1970, 1997), a autonomia parece despertar o sentimento de liberdade no aprendiz. Freire (1970), por exemplo, afirma que a autonomia é a liberação da consciência oprimida e deve ser entendida como um direito para a própria produção ou construção de conhecimento. Segundo o educador, "o respeito à autonomia e à dignidade de cada um 
é um imperativo ético e não um favor que podemos ou não conceder uns aos outros" (FREIRE, 1997, p.59).

\section{Autonomia como sistema adaptativo complexo}

Como se pode perceber, ao longo deste trabalho, o termo autonomia não é autoexplicativo, mas complexo, como Benson (1997) sugere, considerando-se a existência de vários elementos e a demanda por mais de uma definição para o termo. No entanto, a complexidade da autonomia vai muito além da problemática para a definição do termo, conforme pode sugerir o uso comum da palavra (noção de algo complicado). De acordo com a teoria do caos/complexidade, a autonomia pode ser vista como um fenômeno que reúne características de sistemas complexos.

Larsen-Freeman (1997) apresenta a ASL como sistema complexo e argumenta que os sistemas complexos têm algumas características em comum. Esses sistemas apresentam (em diferentes graus) as seguintes características: dinamismo, não linearidade, caos, imprevisibilidade, sensibilidade às condições iniciais, abertura, auto-organização, sensibilidade ao feedback e adaptabilidade (LARSEN-FREEMAN, 1997, p.142), discutidas mais detidamente, a seguir.

A primeira característica dos sistemas complexos apontada por Larsen-Freeman (1997) é o dinamismo. Sistemas dinâmicos são aqueles que mudam com o tempo. As mudanças representam a essência da complexidade. Larsen-Freeman e Cameron (2008) destacam que não só os elementos e agentes mudam com o tempo, mas também o modo como os elementos interagem uns com os outros. Segundo as autoras, as alterações podem ser discretas, quando ocorrem em etapas ou estágios, ou contínuas, quando nunca cessam.

A não linearidade - segunda característica dos sistemas complexos - também é uma particularidade desses sistemas. Um sistema não linear é aquele cujo efeito é desproporcional à causa, embora, às vezes, apresente características lineares (LARSEN-FREEMAN, 1997). Em outras palavras, os componentes de um sistema complexo não são independentes, e as relações entre eles não permanecem fixas. Em oposição, as interações entre os elementos e agentes de sistemas linear- 
es são fixas, e as mudanças no sistema são completamente constantes e previsíveis.

A próxima peculiaridade a ser analisada é o caos em sistemas complexos. Para Larsen-Freeman (1997, p.143), ele se refere ao "período em que os sistemas complexos não lineares entram em completa aleatoriedade de forma irregular e imprevisível". ${ }^{10} \mathrm{Na}$ visão de Kumai (1999), o que ocorre é uma aparente aleatoriedade com padrões estruturais. Pode-se até prever um resultado, mas não com precisão de quando ele acontecerá, tampouco como seu próximo estágio se desenvolverá. Essa imprevisibilidade se deve ao fato de o sistema ser sensível às condições iniciais, o que, para Shucart (2003), é uma característica da não linearidade. Para Johnson (2007, p.15), “o sistema exibe fenômenos emergentes que são, geralmente, surpreendentes e podem ser extremos"." Como os sistemas estão longe do equilíbrio, fenômenos inesperados podem acontecer. O elemento surpresa ocorre pelo fato de não ser possível prever o que vai acontecer com o sistema ao se considerar apenas o conhecimento das propriedades de cada agente isoladamente. Tais características nos remetem à ideia do fenômeno do efeito borboleta, em que impactos desastrosos podem ser produtos de pequenas alterações nas condições iniciais.

Um sistema complexo é também aberto, pois permite o fluxo de informação ou energia com o ambiente externo. Essa absorção de energia é fundamental para a emergência de maior complexidade. Johnson (2007, p.16) afirma que "muito mais comum são os sistemas que, de alguma forma, estão em contato com o mundo externo". A abertura significa que um sistema está longe de atingir seu equilíbrio (ou estado estacionário, do inglês steady state). Segundo Davis e Sumara (2006, p.6), "um estado estacionário implica a morte do sistema complexo". Os organismos vivos, por exemplo, necessitam retirar matéria/energia de seu ambiente.

Uma propriedade emergente de sistemas complexos é a autoorganização, em que "cada sistema cria suas próprias determinações e suas próprias finalidades" (MORIN, 2007, p.65). A possibilidade de auto-organização permite que o sistema adapte seu comportamento. Como o sistema comporta trocas materiais/energéticas com o exterior, seus elementos se reorganizam entre si a partir da desordem. A autoorganização é possível devido ao fato de os sistemas complexos serem 
altamente sensíveis ao feedback. Conforme Johnson (2007, p.14), "um acontecimento passado pode influenciar um evento no presente ou ainda um evento pode interferir em outro evento simultâneo em local diferente".

Em relação à última propriedade dos sistemas complexos, Larsen-Freeman (1997) cita Kauffman (1991) para indicar que esses sistemas são também adaptativos devido à capacidade de seleção natural e de auto-organização. Eles aprendem, ao longo do tempo, a reagir ativamente às variações no seu ambiente. Além disso, esses sistemas são adaptativos porque não respondem apenas passivamente aos eventos, mas "eles tentam, de forma ativa, converter tudo o que acontece para a sua própria vantagem" (WALDROP, 1992, p.11). ${ }^{12}$ Para ilustrar a questão da adaptabilidade em sistemas complexos, tome-se como exemplo o cérebro humano. Quando é preciso utilizar algum conhecimento prévio, o cérebro organiza e reorganiza constantemente bilhões de conexões entre neurônios (WALDROP, 1992, p.11).

De forma breve, os sistemas complexos são formados por elementos ou agentes que interagem entre si ao longo do tempo e de formas distintas. A troca de energia entre as partes e com o meio externo permite que os sistemas se auto-organizem de modo que o todo se torna mais complexo. Como os sistemas não são lineares, causa e efeito não assumem uma relação proporcional e também não é possível prever com precisão quando um comportamento aleatório vai ocorrer.

Em estudo sobre autonomia à luz do paradigma da complexidade, Paiva, pesquisadora pioneira, ao tratar de autonomia sob a perspectiva complexa, propõe a seguinte definição:

[...] autonomia é um sistema sócio-cognitivo ${ }^{13}$ complexo, que se manifesta em diferentes graus de independência e controle sobre o próprio processo de aprendizagem, envolvendo capacidades, habilidades, atitudes, desejos, tomadas de decisão, escolhas, e avaliação tanto como aprendiz de língua ou como seu usuário, dentro ou fora da sala de aula (PAIVA, 2006, p.88-89).

A pesquisadora argumenta que autonomia é um fenômeno que compreende inúmeras possibilidades de interações e indeterminações. A autonomia, na visão da pesquisadora, é essencialmente parte da ASL, sendo esses dois sistemas (a autonomia e a aquisição) complexos. Uma característica essencial do sistema complexo ou dinâmico é a auto-orga- 
nização. Nas palavras de Paiva (2006, p.92), “a autonomia do aprendiz pode auto-organizar a aquisição, pois os processos cognitivos e algumas escolhas de aprendizagem dependem dos aprendizes".

Cabe ressaltar que, no sistema complexo que a autonomia representa, há fatores cruciais inter-relacionados, por exemplo, o aprendiz, o professor, a instituição, o material, os contextos social e político, a legislação e a tecnologia. Paiva (2006) destaca que, como a autonomia não é exclusivamente inata, um ou mais desses fatores podem incentivar ou reprimir o desenvolvimento da autonomia.

A partir da proposta de autonomia como sistema adaptativo complexo de Paiva (2006), também se pode descrever a autonomia à luz do paradigma da complexidade. Neste trabalho, utiliza-se o termo "sistema adaptativo complexo" para se fazer referência à autonomia, mais especificamente, à autonomia na aprendizagem de línguas. Primeiramente, é preciso atender à premissa básica de que o sistema de autonomia se inter-relaciona com um sistema mais abrangente, o de aprendizagem de línguas. Em outras palavras, a autonomia pode ser vista como um subsistema desse sistema maior. Em segundo lugar, com base nos teóricos citados na seção anterior, a noção de autonomia a ser aprofundada aqui se aproxima do conceito de responsável pela própria aprendizagem e se distancia da ideia de autodidatismo. Agora, é possível discutir, em detalhe, a definição de autonomia orientada pelas características de sistemas complexos, comentadas a seguir.

Complexidade - há um grande número de componentes e com alto nível de interatividade na autonomia. Alguns desses elementos são: o aprendiz, suas necessidades, desejos, crenças, tempo disponível, material didático, tecnologia, professor, instituição de ensino, colegas de classe, etc.

Dinamismo - dependendo do modo e da intensidade com que os elementos do sistema interagem, a autonomia pode atingir diferentes níveis. Por exemplo, o grau de proficiência que o aprendiz possui ao utilizar determinado recurso tecnológico, aliado ao tempo que ele tem disponível para explorá-lo, pode contribuir favorável ou desfavoravelmente para o desenvolvimento de sua autonomia. Se um aluno desconhece as funções principais de um dicionário eletrônico, mas tem tempo suficiente para aprender a usá-lo, ele poderá consultar o significado de uma palavra desconhecida e, talvez, buscar o significado de outras que 
tenha curiosidade. Entretanto, se o mesmo aluno não tem tempo para descobrir como esse dicionário funciona, ele não conseguirá identificar o significado da palavra desconhecida.

Não linearidade - as interações entre os elementos não são fixas e, dessa forma, o efeito não é proporcional à causa. Dado o mesmo contexto de aprendizagem (condições iniciais), a autonomia pode se manifestar de formas diferentes. Ainda em relação ao exemplo anterior (o uso do dicionário eletrônico), um aprendiz que não conseguiu utilizá-lo pode-se sentir desestimulado e interromper a aprendizagem ou, de forma contrária, ter maior determinação para conhecer o significado da palavra desconhecida e recorrer a outro recurso, por exemplo, um dicionário impresso, um membro da família que tem um conhecimento avançado no idioma ou um colega de classe com um amplo vocabulário da língua.

Abertura - a autonomia é dinâmica e não apenas realiza interação entre componentes dentro de seu sistema, mas também interage com o ambiente externo, ou seja, com outros sistemas tal como a aprendizagem. Como o conceito de autonomia aqui se afasta da noção de autodidatismo, entende-se que há fluxo de informações entre o aprendiz e o professor, o aprendiz e outro colega, o aprendiz e o material didático ou o aprendiz e uma tecnologia. Quando esses elementos interagem, o aprendiz pode fazer escolhas que vão interferir no processo de aprendizagem. Isso só acontece porque o sistema é aberto, ou seja, vivo.

Caos, imprevisibilidade, sensibilidade às condições inicias - fenômenos inesperados podem acontecer para fomentar ou inibir a autonomia. Um exemplo é a imprevisibilidade do desempenho de um grupo de alunos em uma discussão mediada por um aprendiz mais competente. Em um contexto de aprendizagem baseada em projetos, costuma haver um aluno que atua como mediador das discussões do seu grupo. As discussões são produtivas, pois os integrantes do grupo se sentem encorajados a participar dos debates promovidos por esse debatedor. O que acontecerá se um dia esse debatedor não estiver presente? E se ele entrar em conflito com os demais integrantes do grupo? E se o professor eleger outro aluno para a função de debatedor? Não é possível antecipar com precisão o que acontecerá.

Auto-organização, adaptabilidade, sensibilidade ao feedback - a autonomia pode adaptar seu comportamento, isto é, as interações entre 
seus componentes, para que ela continue a se desenvolver. Ainda sobre o exemplo anterior, em resposta à ausência da figura do debatedor, as devidas regulações feitas no sistema (tal como a escolha, por parte do grupo ou do professor, de outro aluno experiente para ser temporariamente debatedor) poderão interferir positivamente na manutenção da autonomia.

\section{Considerações finais}

Como se viu ao longo deste trabalho, procurou-se traçar o panorama contemporâneo de pesquisas sobre a questão da autonomia no contexto de ensino-aprendizagem de línguas no Brasil e, em seguida, destacar as concepções de autonomia nas teorias de ASL - behaviorismo, gramática universal, aculturação e socioculturalismo. Em seguida, a partir de algumas definições consagradas para o referido termo, foi apresentada a visão de autonomia na aprendizagem de línguas como sistema adaptativo complexo.

De forma resumida e contemplando as características de sistemas complexos descritas anteriormente, destaca-se a seguinte noção de autonomia no ensino-aprendizagem de línguas: um sistema adaptativo complexo, subsistema da aprendizagem, que expressa o dinamismo de um aprendiz que, através de constante auto-organização do sistema, consegue manter ativas as interações com diversos outros componentes da aprendizagem.

O entendimento da autonomia como um fenômeno complexo implica a necessidade de estar atento ao turbilhão de inter-relações no sistema de ASL e, consequentemente, à sua dinamicidade. Para o professor de línguas, por exemplo, isso significa perceber que suas ações causam perturbações diferentes em cada aluno e em cada contexto de ensino-aprendizagem. O ser humano é altamente complexo e cada um carrega histórias de aprendizagem que são únicas. Reconhecer essa complexidade é o primeiro passo para que o professor esteja sensível às histórias e às necessidades de cada aluno. 


\section{NOTAS}

1 Este artigo é um recorte de pesquisa desenvolvida em tese de doutorado (FRANCO, 2013). Recomenda-se que o leitor consulte o texto original se desejar maior detalhamento sobre os assuntos aqui tratados.

2 O Projeto AMFALE é coordenado pela professora Vera Menezes, e as narrativas estão disponíveis em: <http://www.veramenezes.com/amfale/index.html>.

3 Trecho original: "the person learns alone [...] without support from a teacher, advisor, or institution" (OXFORD, 2003, p.82).

4 Trecho original: "the situation in which the learner is totally responsible for the decisions concerned with his/ her learning and the implementation of these decisions" (DICKINSON, 1987, p.11).

5 Trecho original: "mental and emotional characteristics of learners, who are viewed either as individuals (individual psychology)" (OXFORD, 2003, p.83).

6 Trecho original: "gain autonomy in the language by exploring it and making choices" (LARSEN-FREEMAN, 2000, p.65).

7 Trecho original: "take responsibility for their own learning" (LARSEN-FREEMAN, 2000, p.65).

8 Trecho original: "members of a rather generalized social or cultural group (social psychology)” (OXFORD, 2003, p.83).

9 Trecho original: "the individual is not as central as community participation; and this perspective emphasizes the context of autonomy rather than the individual exercising it" (OXFORD, 2003, p.87).

10 Trecho original: "the period of complete randomness that complex nonlinear systems enter into irregularity and unpredictability” (LARSEN-FREEMAN, 1997, p.143). 11 Trecho original: "the system exhibits emergent phenomena which are generally surprising, and may be extreme" (JOHNSON, 2007, p.15).

12 Trecho original: "they actively try to turn whatever happens to their advantage" (WALDROP, 1992, p.11).

13 Para Paiva (2006), um sistema sociocognitivo é um conjunto de fatores sociais que interferem positiva ou negativamente com estados e processos mentais do aprendiz. 


\section{REFERÊNCIAS}

BENSON, P. Teaching and researching autonomy in language learning. London: Longman, 2001.

BENSON, P. The philosophy and politics of learner autonomy. In: BENSON, P.; VOLLER, P. (Eds.). Autonomy and independence in language learning. London and NY: Longman, 1997. p.18-34.

BENSON, P.; VOLLER, P. Introduction: autonomy and independence in language learning. In: BENSON, P.; VOLLER, P. (Eds.). Autonomy and independence in language learning. London and NY: Longman, 1997. p.1-12.

BRUCE, B.; HOGAN, M. The disappearance of technology: Toward and ecological model of literacy. In: REINKING, D.; McKENNA, M.; LABBO, L.; KIEFFER, R. (Eds.). Handbook of literacy and technology: transformations in a post-typographical world. Hillsdale, NJ: Erlbaum, 1999. p.269-281.

CHOMSKY, N. Review of B. F. Skinner, Verbal Behavior. Language, (S.1), n.35, p.26$58,1959$.

COTTERALL, S. Readiness for autonomy: investigating learner beliefs. System, (S.l), v.23, n.2, p.195-205, 1995.

DAVIS, B.; SUMARA, D. Complexity and education: inquiries into learning, teaching and research. Mahwah: Lawrence Erlbaum Associates, 2006.

DULAY, H.; BURT, M.; KRASHEN, S. Language two. New York, NY: Oxford University Press, 1982.

DICKINSON, L. Autonomy and motivation: A literature review. System, (S.1), v.23, n.2, p.165-174, 1995.

DICKINSON, L. Self-instruction in language learning. Cambridge: Cambridge University Press, 1987.

FERNANDES, V. L. D. As crenças e a práxis de professores de língua inglesa em formação e o aprendizado autônomo. 219f. 2005. Tese (Doutorado em Letras) - Faculdade de Letras, UFRGS, Porto Alegre, 2005.

FRANCO, Claudio de Paiva. Autonomia na aprendizagem de inglês: um estudo com nativos digitais sob as lentes do caos e da complexidade. 201f. 2013. Tese (Doutorado em Estudos Linguísticos) - Faculdade de Letras, Universidade Federal de Minas Gerais, Belo Horizonte, 2013. Disponível em: <http://claudiofranco.com.br/media/teseclaudiofranco.pdf $>$. Acesso em: 14 ago. 2013.

FRANCO, Claudio de Paiva. Por uma abordagem complexa de leitura. In: TAVARES, K.; BECHER, S.; FRANCO, C. (Orgs.). Ensino de Leitura: fundamentos, práticas e reflexões para professores da era digital. Rio de Janeiro: Faculdade de Letras da UFRJ, 2011. p.26-48. Disponível em: <http://www.claudiofranco.com.br/textos/ franco_ebook_leitura.pdf> Acesso em: 02 out. 2012.

FREIRE, P. Pedagogia do oprimido. Rio de Janeiro: Paz e Terra, 1970.

FREIRE, P. Pedagogia da autonomia: saberes necessários à prática educativa. 35.ed. Rio de Janeiro: Paz e Terra, 1997.

GIBSON, J. J. The ecological approach to visual perception. Hillsdale, New Jersey: Lawrence Erlbaum, 1986.

HAYTHORNTHWAITE, C.; KAZMER, M.; ROBINS, J.; SHOEMAKER, S. 
Community development among distance learners: temporal and technological dimensions. Journal of Computer-Mediated Communication, (S.1), v.6, n.1, 2000. Disponível em: <http://jcmc.indiana.edu/vol6/issue1/haythornthwaite.html> Acesso em: 25 out. 2011.

HOLEC, H. Autonomy and foreign language learning. Oxford: Pergamon, 1981.

JOHNSON, Neil. Simply complexity: a clear guide to complexity theory. Oxford: Oneworld, 2007.

KAUFFMAN, S. Antichaos and adaptation. Scientific American, (S.l), p.78-84, aug. 1991. KERN, R.; WARSCHAUER, M. Theory and practice of network-based language teaching. In: WARSCHAUER, M.; KERN, R. (Eds.). Network-based language teaching: concepts and practice. New York: Cambridge University Press, 2000 p.1-19. Disponível em: <http://www.gse.uci.edu/person/warschauer_m/docs/nbltintro.pdf $>$ Acesso em: 10 nov. 2010.

KUMAI, W. Group dynamics at the edge of chaos: Toward a complex adaptive systems theory of language learning. Journal of Nanzan Junior College (Bulletin of Universities and Institutes), (S.1), 1999.

LARSEN-FREEMAN, D. Chaos/complexity science and second language acquisition. Applied Linguistics, Oxford, Oxford University Press, v.18, n.2, p.141-165, 1997.

LARSEN-FREEMAN, D. Techniques and principles in language teaching (second edition). Oxford: Oxford University Press, 2000.

LARSEN-FREEMAN, D.; CAMERON, L. Complex systems and applied linguistics. Oxford: Oxford University Press, 2008.

LITTLE, D. Learner autonomy: definitions, issues and problems 1. Dublin: Authentic, 1991. MAGNO E SILVA, W. A model for the enhancement of autonomy. Delta, São Paulo, v.24, n. special, p.469-492, 2008. Disponível em:

<http: / / www.scielo.br/scielo.php?script=sci_arttext\&pid=S010244502008000300005\&lng=en\&nrm=iso\&tlng=en>. Acesso em: 02 out. 2012.

MOURA FILHO, A. C. L. Pelo inglês afora: carreira profissional e autonomia na aprendizagem de inglês como língua estrangeira. 286f. 2005. Tese (Doutorado em Estudos Linguísticos) - Faculdade de Letras, Universidade Federal de Minas Gerais, Belo Horizonte, 2005.

MITCHELL, R.; MYLES, F. Second language learning theories. London: Arnold, 2004.

MORIN, E. Introdução ao pensamento complexo. 3ed. Porto Alegre: Sulina, 2007.

NICOLAIDES, C. S. Crenças de professores estagiários em sua caminhada em busca da aprendizagem autônoma. In: SILVA, K. A. (Org.). Crenças, discursos \& linguagem. Campinas: Pontes, 2010. v.1, p.267-294.

NICOLAIDES, C. S. Inglês no contexto de Hong Kong: um olhar de fora em relação ao aprendizado autônomo de línguas. In: FREIRE, Maximina; ABRAHÃO, Maria Helena; BARCELOS, Ana Maria. (Orgs.). Linguística aplicada e contemporaneidade. São Paulo: Pontes, 2005. v.1, p.155-172.

NICOLAIDES, C. S. A busca da aprendizagem autônoma de lingua estrangeira no contexto acadêmico. 232f. 2003. Tese (Doutorado em Letras) - Faculdade de Letras, UFRGS, Porto Alegre, 2003.

OXFORD, R. Toward a more systematic model of L2 learner autonomy. In: PALFREYMAN, D.; SMITH, R. C. (Eds.). Learner autonomy across cultures: language educa- 
tion perspectives. Basingstoke: Palgrave Macmillan, 2003. p.75-91.

PAIVA, V. L. M. O. Identity, motivation, and autonomy from the perspective of complex dynamical systems. In: MURRAY, G.; GAO, X.; LAMB, T. Identity, motivation and autonomy in language learning. Bristol, Buffalo, Toronto: Multilingual Matters, 2011. Disponível em: < http://www.veramenezes.com/identity.pdf>. Acesso em: 02 out. 2012.

PAIVA, V. L. M. O. propiciamento (affordance) e autonomia na aprendizagem de língua inglesa. In: LIMA, D. C. Aprendizagem de língua inglesa: histórias refletidas. Vitória da Conquista: Edições UESB, 2010. Disponível em:

http://www.veramenezes.com/affordance.pdf. Acesso em: 03 out. 2012.

PAIVA, V. L. M. O. Autonomia e complexidade. Linguagem \& Ensino, Pelotas, v.9, n.1, p.77-127, 2006. Disponível em:

http://rle.ucpel.tche.br/php/edicoes/v9n1/vera_paiva.pdf. Acesso em: 25 out. 2011. PAIVA, V. L. M. O. Autonomia e complexidade: uma análise de narrativas de aprendizagem. In: FREIRE, M. M; ABRAHÃO, M. H. V; BARCELOS, A. M. F (Orgs.). Linguística aplicada e contemporaneidade. Campinas e São Paulo: Pontes e ALAB, 2005a. p.135-153

PAIVA, V. L. M. O. Autonomy in second language acquisiton. SHARE: An Electronic Magazine by Omar Villarreal and Marina Kirac, n.146, ano 6, May 6th 2005b. Disponível em: < http://www.veramenezes.com/autoplex.htm>. Acesso em: 02 out. 2012.

PAIVA, V. L. M. O. A www e o ensino de inglês. Revista Brasileira de Linguística Aplicada, v.1, n.1, 2001. Disponível em: http://www.veramenezes.com/www.htm. Acesso em: 25 out. 2011.

PAIVA, V. L. M. O.; BRAGA, J. C. F. The complex nature of autonomy. Delta, São Paulo, v.24, n. especial, p.441-468, 2008.

PENNYCOOK, A. Cultural alternatives and autonomy. In: BENSON, P.; VOLLER, P. (Eds.). Autonomy and independence in language learning. New York: Addison Wesley Longman, 1997. p.35-53.

ROGERS, C. R. Freedom to learn. Colombus, OH: Charles E. Merril, 1969.

ROSSA, A. A; ROSSA, C. R. Paradigma conexionista e o ensino de língua estrangeira. Letras de Hoje. Porto Alegre, v.44, n.3, p.53-59, jul./set. 2009. Disponível em: http://revistaseletronicas.pucrs.br/ojs/index.php/fale/article/viewFile/5764/4184. Acesso em: 12 dez. 2011.

RUMELHART, D.; MCCLELLAND, J. On learning the past tense of English verbs. In: MCCLELLAND, J.; RUMELHART, D. (Eds.). Parallel distributed processing: explorations in the microstructure of cognition. Cambridge, MA: MIT Press, 1986. v.2: Psychological and biological models, p.216-271.

SCHETZER, H.; WARSCHAUER, M. An electronic literacy approach to networkbased language teaching. In: WARSCHAUER, M.; KERN, R. (Eds.). Network-based language teaching: concepts and practice. New York: Cambridge University Press, 2000. p.171185. Disponível em: http://gse.uci.edu/person/warschauer_m/docs/nblt.pdf. Acesso em: 02 out. 2012.

SHUCART, S. CALL, Complexity and language emergence. The erraced labyrinth. Disponível em: <http://molly.honjyo.reccs.akita-pu.ac.jp/tl/papers/paper2.html>. Acesso em: 06 abr. 2012. 
SCHUMANN, J. H. The acculturation model for second-language acquisition. In: GINGRAS, R. C. Second language-acquisition \& foreign language teaching. Washington: Center for Applied Linguistics, 1978. p.27-49.

SPRENGER, T. M.; WADT, M. P. S. Autonomy development and the classroom: reviewing a course syllabus. Delta, São Paulo, v.24, n. special, p.551-576, 2008. Disponível em: http://www.scielo.br/scielo.php?script=sci_arttext\&pid=S010244502008000300009\&lng=en\&nrm=iso. Acesso em: 02 out. 2012.

SPRENGER, T. M. Conscientização e autonomia em formaşão on-line de professores. $315 \mathrm{f}$. 2012. Tese (Doutorado Linguistica Aplicada e Estudos da Linguagem) - Faculdade de Letras, USP, São Paulo, 2004. Disponível em: http://www4.pucsp.br/pos/lael/laelinf/teses/tese_teresprenger.zip. Acesso em: 02 out. 2012.

VYGOTSKY, L. S. Mind in society: the development of higher psychological processes. Cambridge, MA: Harvard University Press, 1978.

WALDROP, M. Complexity: the emerging science at the edge of order and chaos. New York: Simon \& Schuster, 1992.

WARING, R. Connectionism and second language vocabulary. 1996. Disponível em: http://www.fltr.ucl.ac.be/fltr/germ/etan/bibs/vocab/connect.html. Acesso em: 12 dez. 2011.

WARSCHAUER, M. A developmental perspective on technology in language education. Tesol Quarterly, (S.l), v.36, n.3, p.453-475, 2002. Disponível em:

http://www.gse.uci.edu/person/warschauer_m/docs/developmental.pdf. Acesso em: 25 out. 2011.

Recebido: $23 / 10 / 2012$

Aprovado: 19/08/2013

Contato:

Faculdade de Letras

Universidade Federal do Rio de Janeiro

Avenida Brigadeiro Trompowski

Ilha do Fundão

CEP 21941-590

Rio de Janeiro | RJ | Brasil 